\title{
Rapid response of a grassland ecosystem to an experimental manipulation of a keystone rodent and domestic livestock
}

\author{
Ana D. Davidson,,${ }^{1,2,5}$ Eduardo Ponce, ${ }^{1}$ David C. Lightfoot,${ }^{2}$ Ed L. Fredrickson, ${ }^{3}{ }^{\text {James H. }}$ Brown,${ }^{2}$ \\ Juan Cruzado, ${ }^{1}$ Sandra L. Brantley, ${ }^{2}$ Rodrigo Sierra-Corona, ${ }^{1}$ Rurik List, ${ }^{1}$ David Toledo, ${ }^{3,4}$ \\ and Gerardo Ceballos ${ }^{1}$ \\ ${ }^{1}$ Instituto de Ecología, Universidad Nacional Autónoma de México, México, DF 04510 Mexico \\ ${ }^{2}$ Department of Biology, University of New Mexico, Albuquerque, New Mexico 87131 USA \\ ${ }^{3}$ United States Department of Agriculture, Agricultural Research Service, Jornada Experimental Range, \\ Las Cruces, New Mexico 88003 USA \\ ${ }^{4}$ Ecosystem Science and Management, Texas A\&M University, 2138 TAMU, College Station, Texas 77840 USA
}

\begin{abstract}
Megaherbivores and small burrowing mammals commonly coexist and play important functional roles in grassland ecosystems worldwide. The interactive effects of these two functional groups of herbivores in shaping the structure and function of grassland ecosystems are poorly understood. In North America's central grasslands, domestic cattle (Bos taurus) have supplanted bison (Bison bison), and now coexist with prairie dogs (Cynomys spp.), a keystone burrowing rodent. Understanding the ecological relationships between cattle and prairie dogs and their independent and interactive effects is essential to understanding the ecology and important conservation issues affecting North American grassland ecosystems. To address these needs, we established a long-term manipulative experiment that separates the independent and interactive effects of prairie dogs and cattle using a $2 \times 2$ factorial design. Our study is located in the Janos-Casas Grandes region of northwestern Chihuahua, Mexico, which supports one of the largest remaining complexes of black-tailed prairie dogs $(C$. ludovicianus). Two years of posttreatment data show nearly twofold increases in prairie dog abundance on plots grazed by cattle compared to plots without cattle. This positive effect of cattle on prairie dogs resulted in synergistic impacts when they occurred together. Vegetation height was significantly lower on the plots where both species co-occurred compared to where either or both species was absent. The treatments also significantly affected abundance and composition of other grassland animal species, including grasshoppers and banner-tailed kangaroo rats (Dipodomys spectabilis). Our results demonstrate that two different functional groups of herbivorous mammals, burrowing mammals and domestic cattle, have distinctive and synergistic impacts in shaping the structure and function of grassland ecosystems.
\end{abstract}

Key words: Bos taurus; Chihuahuan Desert; Cynomys ludovicianus; domestic cattle; ecosystem engineers; grasshoppers; grassland; grazing; herbivores; keystone species; prairie dogs; vegetation.

\section{INTRODUCTION}

The ecological role of a species, its Eltonian niche, is played out not in isolation from other species but within the context of an entire community (Leibold 1995). Ecosystems are shaped by these complex interactions among species and their separate and interactive impacts. The importance of species' interactive effects, including effects among different functional groups, is increasingly recognized, yet remains little understood (Helfield and Naiman 2006, Alba-Lynn and Detling 2008).

Mammalian herbivores, both large and small, play important roles in shaping grassland ecosystems (McNaughton 1984, Whicker and Detling 1988, Frank

Manuscript received 22 July 2009; revised 4 February 2010; accepted 10 February 2010; final version received 12 March 2010. Corresponding Editor: T. J. Valone.

${ }^{5}$ E-mail: Davidson@unm.edu et al. 1998, Bakker et al. 2006). Different-sized herbivores often have complementary and additive effects, and the ecological relationships between them can be facilitatory (Ritchie and Olff 1999, Arsenault and Owen-Smith 2002, Olofsson et al. 2004, Bakker et al. 2006). In grasslands around the world, two ubiquitous functional groups of mammalian herbivores, megaherbivores and small burrowing mammals, commonly coexist. They have co-evolved with grasslands and with each other over millions of years, and both have effects far beyond their herbivory, often playing keystone and engineering roles (Owen-Smith 1987, Jones et al. 1994, Power et al. 1996, Frank et al. 1998). As such, the interactive impacts and ecological relationships between these groups may be fundamentally important to the structure and function of grassland ecosystems, but remain poorly understood. Understanding their interactive roles in the context of human activities is especially important, as humans are greatly altering the species composition, populations, and ecological roles of both 
groups of herbivores (Owen-Smith 1987, Jackson 1988, Lai and Smith 2003, Suttie et al. 2005, Miller et al. 2007).

Megaherbivores, such as bison (Bison bison), African ungulates, and elephants (Loxodonta africana), exert strong controls through their grazing, browsing, migrations, and wallowing (Owen-Smith 1987, Power et al. 1996, Frank et al. 1998, Knapp et al. 1999). Across grassland landscapes they create expansive grazing lawns and wallows, increasing landscape heterogeneity, biodiversity, and nutrient cycling rates. They can be important prey, and some, like elephants, create open grassland and habitat for other animals by browsing shrubs (Pringle 2008). Today, however, most grasslands are dominated by domestic livestock that have replaced free-ranging herds of megaherbivores (Suttie et al. 2005). In North America, for example, domestic cattle (Bos taurus) have supplanted native bison throughout most of their historic range. On one hand, improperly managed livestock grazing can damage grasslands by overgrazing, vegetation trampling, and dispersal of invasive plants, and has resulted in extensive degradation and desertification of grasslands worldwide (Schlesinger et al. 1990, Suttie et al. 2005). On the other hand, cattle are ecologically similar to bison and other ungulates, and may partially play the functional role of megaherbivores when native species are absent (Towne et al. 2005, Derner et al. 2009).

Burrowing mammals, including plains vizcachas (Lagostomus maximus), Siberian marmots (Marmota sibirica), plateau pikas (Ochotona curzoniae), ice rats (Myotomys sloggetti), gophers (Geomys and Thomomys spp.), and prairie dogs (Cynomys spp.; see Plate 1), also have important effects on grasslands through their herbivory (Huntly and Inouye 1988, Whicker and Detling 1988, Branch et al. 1999, Smith and Foggin 1999, Mokotjomela et al. 2009, Yoshihara et al. 2010). Unlike megaherbivores, however, they are sedentary and have large impacts through the engineering of mounds and extensive belowground burrow systems (Jones et al. 1994, Whitford and Kay 1999). In the central grasslands of North America, for example, prairie dogs (Cynomys spp.) create unique islands of habitat by consuming grass, maintaining a low, dense turf of forbs and grazing-tolerant grasses, and dotting their colonies with numerous mounds and deep burrow systems (Whicker and Detling 1988, Davidson and Lightfoot 2008). In so doing, prairie dogs provide key habitat for many grassland animals, enhance the nutritional quality of forage, which attracts large herbivores to their colonies, and provide important prey for predators (Whicker and Detling 1988, Kotliar et al. 2006, Davidson and Lightfoot 2007, Davidson et al. 2008). They also help maintain grasslands by clipping shrubs (Weltzin et al. 1997, Ceballos et al. 2010).

A critical issue for conservation of grasslands around the world is the need to maintain the important functional role of keystone burrowing mammals, like prairie dogs, while simultaneously managing for livestock production (Lai and Smith 2003, Bagchi et al. 2006, Miller et al. 2007, Yoshihara et al. 2010). This raises the question of how the ecology of burrowing mammals is modified by and interacts with that of livestock. The relationships between prairie dogs and cattle and their interactive impacts may be similar to those between bison and prairie dogs (Coppock et al. 1983, Cid et al. 1991, Fahnestock and Detling 2002), but have been surprisingly little studied (Detling 2006). Despite little direct evidence, competition with cattle has been used to justify extensive programs to eradicate prairie dogs and other herbivorous rodents from grasslands throughout the world. In the United States, a century of prairie dog "pest control" programs have reduced populations to $2-5 \%$ of their historic numbers and still continue today (Miller et al. 2007). In the Janos-Casas Grandes region of northern Chihuahua, Mexico, where one of the largest black-tailed prairie dog complexes remains, much of this once-extensive Chihuahuan Desert grassland has been invaded by mesquite (Prosopis glandulosa) and degraded to annual grassland (Ceballos et al. 2010). This has been attributed to extremely high stocking densities of cattle and poor land management practices (Ceballos et al. 2010) that do not consider the relationships between cattle and prairie dogs.

Large-scale, long-term experimental studies are essential to disentangle the roles of cattle and prairie dogs, but such studies are currently lacking (Detling 2006, Curtin 2008). We established a long-term, large-scale experiment in the Janos grasslands that simultaneously manipulates both cattle and prairie dogs $(C$. ludovicia$n u s)$. We address the following core questions. (1) Do prairie dogs and cattle have distinctive effects on vegetation structure and plant and animal community composition? (2) Do prairie dogs and cattle together have a larger combined effect on these ecosystem components than either species alone? (3) Does the presence of cattle affect the abundance of prairie dogs? And (4) What are the implications of their interactions and combined effects for conservation and management?

We motivate these experiments with a conceptual model that predicts the separate and interacting roles of megaherbivores and small burrowing mammals on grassland ecosystems, using the Janos ecosystem as our example (Fig. 1). The key features of this model are: (1) megaherbivores affect grassland ecosystems primarily by grazing and browsing herbaceous vegetation, but also by trampling and/or wallowing; (2) smaller burrowing mammals affect the grassland primarily by ecosystem engineering, including burrowing in the soil and clipping vegetation, but also by grazing; (3) megaherbivores and burrowing mammals indirectly affect each other through their impacts on vegetation and soils, resulting in interactive effects on the grassland; and (4) humans control populations of both groups. We use our 


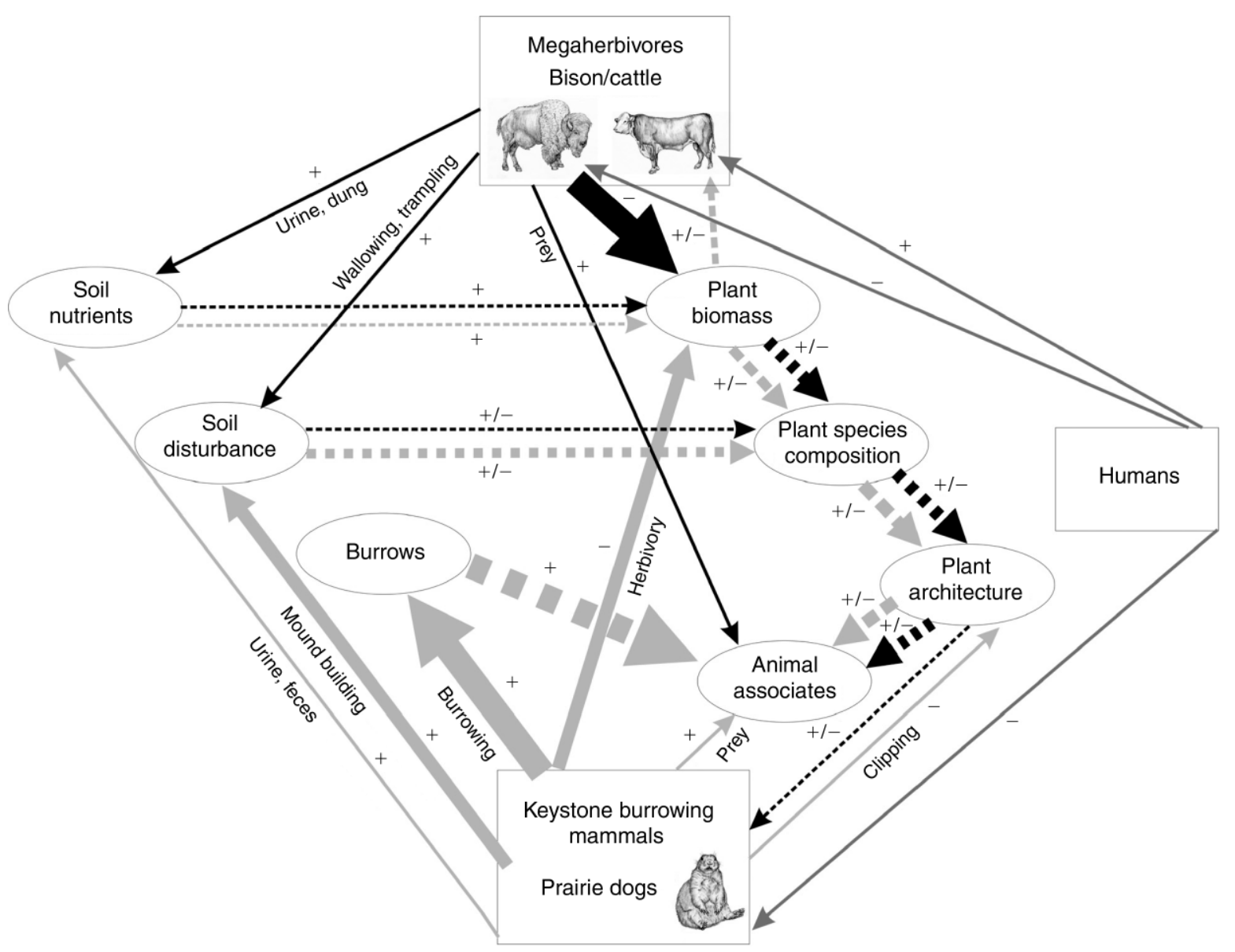

FIG. 1. Conceptual model showing the separate and interactive effects of megaherbivores (e.g., bison and cattle) and keystone burrowing mammals (e.g., prairie dogs) on grassland ecosystems. Black arrows indicate effects of bison/cattle, light-gray arrows indicate effects of prairie dogs, and medium-gray arrows indicate effects of humans. Solid arrows represent direct effects, while dashed arrows represent indirect effects. The + and - symbols indicate positive and/or negative effects. The presence of both bison/ cattle and prairie dog arrows indicates an interactive impact. Bison, cattle, and prairie dog drawings are by Sharyn N. Davidson.

experiment to evaluate this general model, which could be modified to account for effects of different herbivore taxa and environmental conditions in grassland ecosystems throughout the world. Our work here helps elucidate the relationships and interactive roles of these important herbivores, key to understanding the impact of human activities on global grassland decline and implementing proper management.

\section{Study Area}

Our study was conducted in the Janos-Casas Grandes region of northwestern Chihuahua, Mexico, located $75 \mathrm{~km}$ south of the United States-Mexico border. The study site is located on the Nature Conservancy's El Uno Ecological Reserve within the Báscula prairie dog colony $\left(30^{\circ} 54^{\prime} \mathrm{N}, 108^{\circ} 26^{\prime} \mathrm{W} ; 1400\right.$ $\mathrm{m}$ elevation), the third largest colony in the region (2000 ha). The reserve was grazed extensively by cattle for decades, but in 2004 cattle were removed to allow vegetation recovery. Drought coupled with extensive livestock overgrazing in this region of the northern Chihuahuan Desert has caused a shift from a perennial grassland to a largely annual grassland (Ceballos et al. 2010). The study site is in a broad basin, with a sandy loam soil surface texture and sandy clay loam subsurface. Vegetation is dominated by the annual grasses sixweeks threeawn (Aristida adscensionis), needle grama (Bouteloua aristidoides), sixweeks grama (B. barbata), and numerous forbs. Perennial grasses present include poverty threeawn (Aristida divaricata), ear muhly (Muhlenbergia arenacea), vine mesquite (Panicum obtusum), and tobosagrass (Pleuraphis mutica), with some blue grama (B. gracilis). Mean annual precipitation is $306 \mathrm{~mm}$, with most occurring during the summer monsoon period. Temperatures range from $-15^{\circ} \mathrm{C}$ in winter to $50^{\circ} \mathrm{C}$ in summer, with a mean annual temperature of $15.7^{\circ} \mathrm{C}$. 


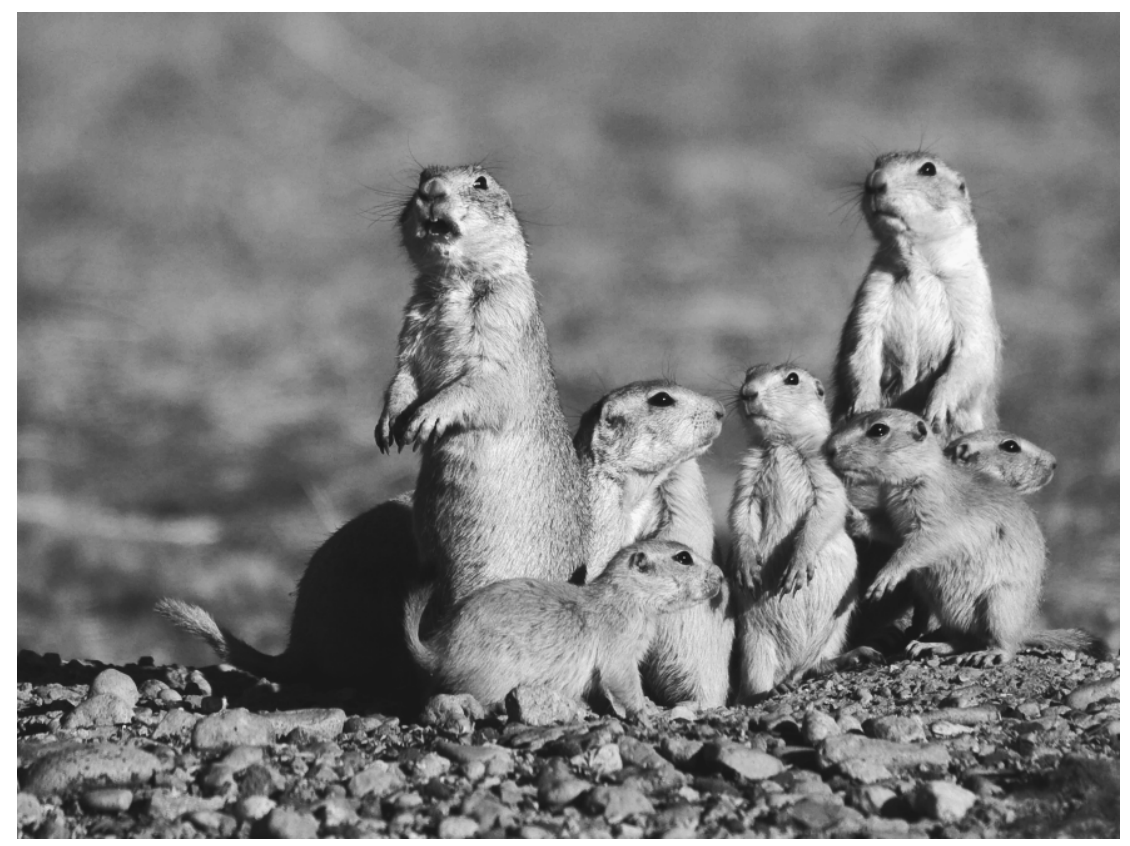

Plate 1. Black-tailed prairie dog (Cynomys ludovicianus mexicanus) coterie taken in the Janos Biosphere Reserve, Chihuahua, Mexico. Photo credit: R. Sierra-Corona.

\section{Methods \\ Experimental design}

We established four replicate blocks of experimental plots, for a total of 16 plots in an area with similar soil type, plant species composition, and initial prairie dog densities (Appendices A and B). The study site had not been grazed by cattle for two years prior to the initiation of the study. Each block had the following $2 \times 2$ factorial design: presence of prairie dogs and cattle $(+\mathrm{P}+\mathrm{C})$, cattle only $(-\mathrm{P}+\mathrm{C})$, prairie dogs only $(+\mathrm{P}-\mathrm{C})$, and where neither species was present $(-\mathrm{P}-\mathrm{C})$ (Appendix A). Plot treatments were randomly assigned within each block. Minimum distances between the four replicate blocks of plots were between $50 \mathrm{~m}$ and $150 \mathrm{~m}$ (Appendix B). Each of the four plots in a replicate block was separated by $30 \mathrm{~m}$. Each plot was $50 \times 50 \mathrm{~m}$, with a $6 \times 6$ grid of 36 sampling points systematically positioned at $10-\mathrm{m}$ intervals. Data were collected from 2006 (baseline pretreatment) through 2007 and 2008 (posttreatment).

\section{Experimental treatments}

Prairie dog exclosures, removals, and abundance.Prairie dog exclosures were installed at the end of the first year of the study (late fall 2006). Initially, prairie dogs were present on all plots, and the $-\mathrm{P}+\mathrm{C}$ and $-\mathrm{P}-\mathrm{C}$ treatments were implemented by removing prairie dogs and preventing recolonization by fencing with $2.54-\mathrm{cm}$ poultry netting. This design is superior to establishing $-\mathrm{P}-\mathrm{C}$ and $-\mathrm{P}+\mathrm{C}$ treatments on plots where prairie dogs were initially absent, because it is well known that prairie dog colonies are often associated with distinctive soils and vegetation. The wire mesh extended $0.70 \mathrm{~m}$ aboveground, and was buried $1.25 \mathrm{~m}$ below the soil surface to deter animals from burrowing underneath. A $15.24 \mathrm{~cm}$ wide strip of metal flashing was attached along the top of the poultry wire to prevent prairie dogs from climbing over the fences. To control for potential fence boundary effects, a 5-m buffer was designated between the fence and sampling areas within the study plots (Appendix B). Litter accumulation along the fence was routinely removed. The poultry netting with $2.54 \mathrm{~cm}$ diameter mesh excluded prairie dogs, but allowed access by all other rodents and small desert cottontail rabbits (Sylvilagus audubonii) (Appendix C). The fence height of $0.70 \mathrm{~m}$ allowed predators and adult rabbits to jump over the fences (J. H. Brown, unpublished data; the authors of this study also observed this behavior). Desert cottontail numbers were low in the area. Counts of individuals during prairie dog observations amounted to 10 individuals over the study period, and fecal pellets showed no significant differences among plots.

During late fall of 2006, the exclusion treatments were initiated by removing prairie dogs from the $-\mathrm{P}+\mathrm{C}$ and $-\mathrm{P}-\mathrm{C}$ plots. Animals were trapped using Tomahawk live traps and relocated elsewhere within El Uno Ecological Reserve. Plots $-\mathrm{P}+\mathrm{C}$ and $-\mathrm{P}-\mathrm{C}$ were monitored monthly thereafter, and prairie dogs entering the plots were removed as necessary to maintain the exclusion treatments.

Prairie dogs were visually counted and mapped within and around each of the study plots during mid-spring and early fall of each year from 2006 to 2008 to monitor 
populations on the treatment plots. Prairie dogs tend not to occur uniformly across a colony; rather, they are clustered in distinct coteries (territorial family groups). As a result, prairie dogs were patchily distributed within and/or along the edges of our plots (Appendix D). Therefore, we mapped and counted all prairie dogs associated with coteries that utilized the study plots. As an additional measure, we also counted only those animals observed within the boundaries of each of the study plots (Appendix D). Although both counts provided similar abundance trends, those that included all members of the coteries best represented the number of animals that actually used the study plots (Fig. 2).

During each spring and fall sampling period, an observer was stationed in an elevated blind located in the center of each block. Visual counts and locations of prairie dogs were mapped on two consecutive mornings and the intervening evening. Black-tailed prairie dog coterie groups were very distinct, making counting of individuals simple and repeatable (Appendix D). Live trapping was not performed in order to minimize human impact.

Cattle treatment.-Cattle were placed into the $+\mathrm{P}+\mathrm{C}$ and $-\mathrm{P}+\mathrm{C}$ plots to simulate realistic levels of both grazing and trampling under a moderate winter grazing regime (see Appendix E). Beginning in the winter (January) of 2007 , dry matter forage availability on each plot was estimated by clipping $24,0.5-\mathrm{m}^{2}$ quadrats $2 \mathrm{~cm}$ above the soil surface. Clipped plant material was dried at $40^{\circ} \mathrm{C}$ for 48 hours and then weighed. Available forage for each $+\mathrm{P}+\mathrm{C}$ and $-\mathrm{P}+\mathrm{C}$ plot was calculated, and then grazed by crossbred beef cows (B. taurus). Beef cows used in this study were primarily of British (Angus, Hereford) and continental (Limousin and Charolais) breeds raised on adjacent and/or nearby pastures, and accustomed to the electric fencing used to confine them within plots. Based on forage availability and cow body mass, a number of cows were selected to remove $40 \%$ of the available forage during a four-hour period. Based on nearly a century of research on similar desert grassland associations, conservative grazing not exceeding $40 \%$ utilization is recommended for these sites, with these upland species recommended for winter grazing (Paulsen and Ares 1962, Holechek et al. 1994. Selecting a four-hour duration during the morning period increased the likelihood of normal grazing and limited the effects of trampling (Gregorini et al. 2008). To further limit the effects of trampling, cattle were not placed in plots for 5-7 days following a precipitation event. Forage availability was estimated immediately following grazing to estimate actual utilization.

\section{Plant and animal measurements}

Vegetation.-Percent live plant canopy cover and height of live foliage of all plant species were measured at 10 -m intervals on a $6 \times 6$ grid using $0.25-\mathrm{m}^{2}$ quadrats at the end of the growing season each spring (April) and early fall, (September) 2006-2008. The method was
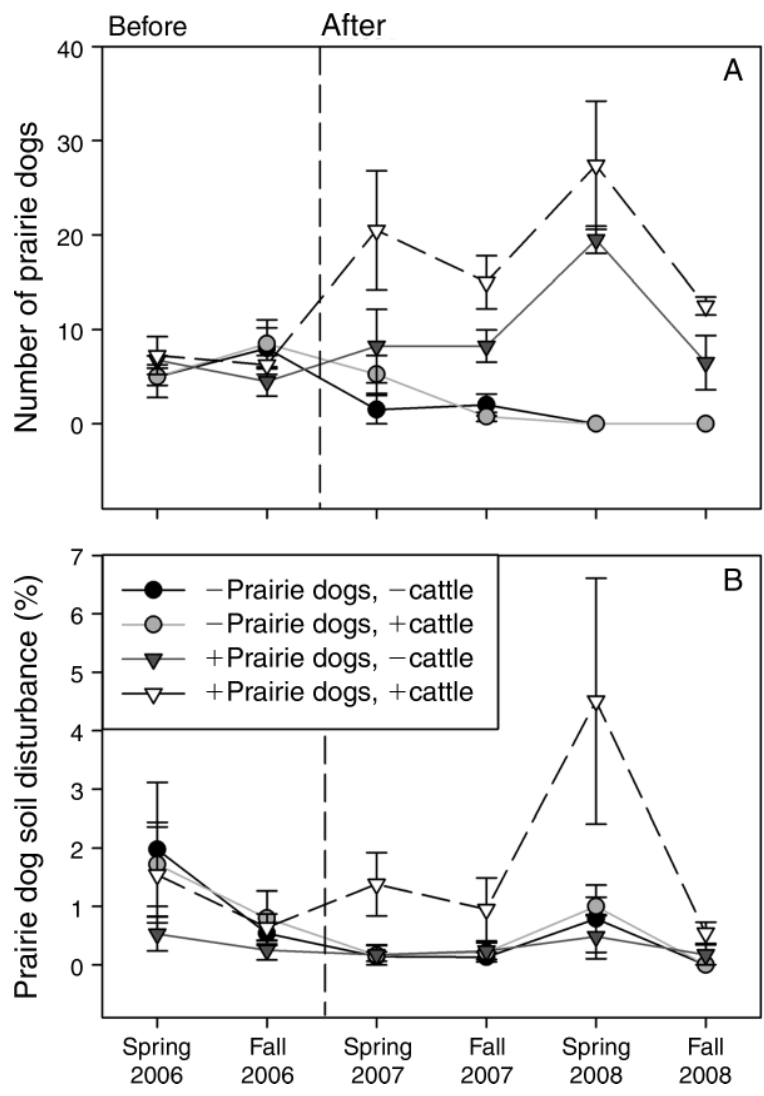

FIG. 2. (A) Numbers of prairie dogs (mean \pm SE) on each of the treatments, based on numbers of animals that use each plot (see Methods: Experimental treatments: Prairie dog exclosures, removals, and abundance for explanation), and (B) prairie dog activity on the study plots as measured by the percent cover of their soil disturbance. There were no significant differences in prairie dog abundance before the treaments were imposed, but subsequently prairie dog abundance was higher on plots where prairie dogs occurred with cattle $(+\mathrm{P}+\mathrm{C})$ than without $(+\mathrm{P}-\mathrm{C})$. Differences (ANOVA: $P<0.05$, $\mathrm{df}=3,15)$ between $+\mathrm{P}+\mathrm{C}$ and $+\mathrm{P}-\mathrm{C}$ plots were present in spring 2007 and fall 2008 .

similar to that developed by Huenneke et al. (2001), with plant canopy cover by species measured with subdecimeter ${ }^{2}$ resolution using a gridded frame (Davidson and Lightfoot 2006). Plant identifications of voucher specimens were conducted at the Autonomous University of Chihuahua (UACH) and voucher specimens were deposited at UACH and the National Autonomous University of Mexico (UNAM). To measure peak aboveground plant biomass, plants were clipped to ground level from $0.1 \mathrm{~m}^{2}(20-50 \mathrm{~cm})$ quadrats using a 3 $\times 3$ grid. Locations of clipped quadrats differed each year. Plants were then separated in the laboratory into forbs, grasses, and shrubs, and further separated into live (at time of harvest) and dead material. Samples were dried in paper bags at $50^{\circ} \mathrm{C}$ to a constant mass $(48 \mathrm{~h})$, then weighed.

Grasshoppers.-Grasshoppers were sampled visually each fall from 2006 to 2008 along $1 \times 50 \mathrm{~m}$ strip 
transects, using a $6 \times 1$ grid array. Grasshoppers flushed from the ground were counted and identified to species (Davidson and Lightfoot 2007).

Animal activity.-Percent cover of soil disturbance (i.e., digs, mounds, and tracks) from prairie dogs, banner-tailed kangaroo rats, and pocket gophers (Thomomys bottae), and counts of feces from desert cottontail rabbits were estimated using the $0.25-\mathrm{m}^{2}$ vegetation quadrats as an index of activity of these animals on the plots (Davidson and Lightfoot 2006). Prairie dogs, kangaroo rat, and harvester ant (Pogonomyrmex spp.) mounds also were mapped and counted on each plot at the start of the study (2006).

\section{Data analysis}

All data were assessed for normality, and if needed, normalized by $\log$ transformations and analyzed using SAS version 9.1 (SAS Institute 2005). We applied two complementary statistical approaches to analyze vegetation (plant height, cover, and biomass), animal activity (fecal counts of rabbits, and soil disturbance by prairie dogs, kangaroo rats, and gophers), mounds (of prairie dogs, kangaroo rats, and harvester ants), grasshopper abundance, and prairie dog abundance among the treatment plots. We used Analysis of Variance (ANOVA) to examine the effects separately and a Mixed Model Analysis of Repeated Measures (MM), which included repeated covariance parameter estimates to evaluate these variables over time to determine significant time $\times$ treatment interactions. The fixed effects for each MM were the plot treatment types, time, and the interaction between the treatments and time. Each model included a random block effect, which allowed for correlated responses among plots within blocks. Each MM compared the posttreatment samples to a baseline pretreatment measure, which came from data on prairie dog plots $(+\mathrm{P}-\mathrm{C})$ during spring and/or fall 2006. Among the four treatments, these $+\mathrm{P}-\mathrm{C}$ plots were not manipulated and represented site conditions at the start of the study. Because the power of the MM was low due to few repeated measurements (i.e., 6 seasons, 3 years), we also used ANOVA models with Tukey's adjustments that made multiple range-test comparisons across treatments at each time interval. We pooled spring and fall measurements by each year for plant height and for plant cover to obtain total annual height and cover.

\section{RESULTS \\ Prairie dog abundance}

There were no significant differences among blocks or treatments prior to imposing the treatments, but soon after, prairie dog abundance was higher on plots grazed by cattle $(+\mathrm{P}+\mathrm{C})$ compared to plots without cattle $(+\mathrm{P}-\mathrm{C})$, and this pattern persisted from spring 2007 to fall 2008 (Fig. 2, Appendices D and F). This observation is supported by prairie dog soil disturbance that exhibited a similar relationship between treatments (Fig. 2, Appendix F).
Winter 2005 and spring 2006 were very dry (Appendix G), resulting in no prairie dog offspring in 2006 . The relatively higher numbers of prairie dogs in 2007 and 2008 reflect, in part, a rebound of the prairie dog population following a more normal precipitation and vegetation production regime. Additionally, while prairie dogs were removed from $-\mathrm{P}+\mathrm{C}$ and $-\mathrm{P}-\mathrm{C}$ plots, and exclosure fences were installed to keep prairie dogs out, there were periodic trespassers, especially in the initial posttreatment stages of the study (Fig. 2).

\section{Vegetation response}

Prairie dogs and cattle had dramatic and rapid effects on the vegetation (Figs. 3 and 4; Appendix F). At the start of the study, there were no differences in vegetation among treatments or across blocks. Shortly after implementing the treatments, plant canopy cover and height were substantially lower where both prairie dogs and cattle were present $(+\mathrm{P}+\mathrm{C})$ compared to plots where each occurred alone $(+\mathrm{P}-\mathrm{C},-\mathrm{P}+\mathrm{C})$ or where neither were present $(-\mathrm{P}-\mathrm{C})$ (Fig. 4, Appendix F). Height of grasses and spring and summer forbs were consistently lowest on the $+\mathrm{P}+\mathrm{C}$ plots relative to the others, although significant differences varied between $+\mathrm{P}+\mathrm{C}$ and the other treatments (Appendix F). Canopy cover of forbs and grasses showed no significant differences $(P>0.05)$. The strongest difference was in summer forb height $\left(\mathrm{MM}\right.$, time $\times$ treatment interaction, $F_{6,22.3}=3.30, P=$ 0.018; Fig. 4C). Summer forb height was very similar at the start of the study, but by 2008 forbs were tallest in $-\mathrm{P}-\mathrm{C}$ plots and $-\mathrm{P}+\mathrm{C}$ plots, intermediate in $+\mathrm{P}-\mathrm{C}$ plots, and shortest in $+\mathrm{P}+\mathrm{C}$ plots (Fig. $4 \mathrm{C}$ ). There were no differences in vegetation height or cover between plots where prairie dogs and cattle each occurred alone, compared to where neither occurred (Fig. 4; Appendix F). Some species-level differences in plant canopy cover and height became apparent by 2007 , and continued into 2008. Compared to the $+\mathrm{P}+\mathrm{C}$ plots, Russian thistle (Salsola kali), an exotic forb, was two times taller in the $+\mathrm{P}-\mathrm{C}$ plots, $>2$ times taller in the $-\mathrm{P}+\mathrm{C}$ plots, and $>3$ times taller in the $-\mathrm{P}-\mathrm{C}$ plots (ANOVA, $F_{3,15}=3.08, P=$ 0.08 ; Fig. 3). Despite some notable changes in vegetation structure (i.e., height and canopy cover) there were no significant differences in aboveground biomass among treatments, probably because there was high variability within. Nevertheless, $+\mathrm{P}+\mathrm{C}$ plots consistently had the lowest biomass compared to the other plots in 2007 and $2008(P>0.05)$.

\section{Grasshopper response}

Grasshoppers showed large responses to the removal of prairie dogs and both prairie dogs and cattle (Fig. 5; Appendix F). Prior to the implementation of treatments, there were no significant differences in grasshopper abundance among treatments or blocks. By 2008, overall grasshopper abundance was much higher on plots where prairie dogs were removed, with 

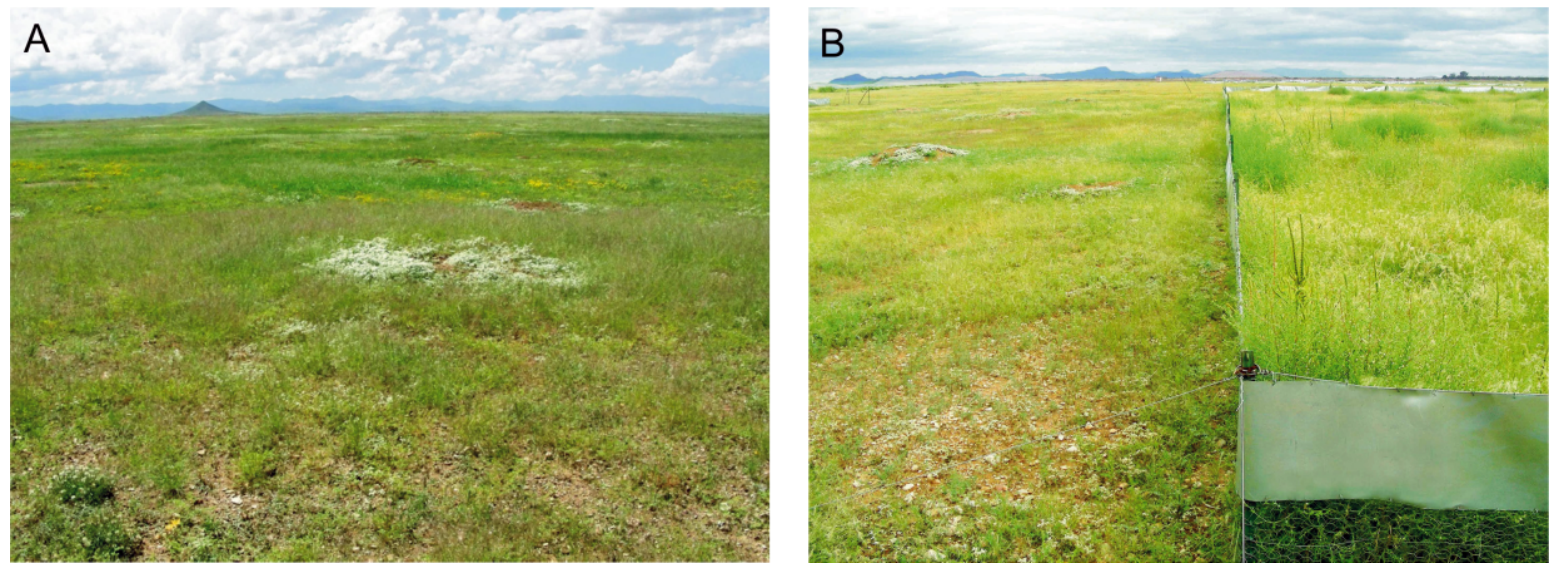

FIG. 3. (A) Photograph of the study site in September 2005, before study plots were constructed and treatments were implemented. (B) Photograph taken in September 2008, 1.5 years after treatments were imposed, showing large differences in plant height and cover within a $-\mathrm{P}-\mathrm{C}$ plot (to the right of the fence) compared to outside the exclosure where only prairie dogs occurred (to the left). Note the tall darker green plants (Russian thistle, Salsola kali) inside. Photo credit: A. D. Davidson.

significant differences between the $-\mathrm{P}-\mathrm{C}$ plots and the $+\mathrm{P}+\mathrm{C}$ and $+\mathrm{P}-\mathrm{C}$ plots (ANOVA, $F_{3,15}=4.69, P=0.03$; MM, $F_{6,19.6}=3.14, P=0.025$; Fig. 5). Much of this was due to one dominant species, Melanoplus lakinus, which by 2008 was $2-3$ times more abundant on the plots where prairie dogs were removed $(-\mathrm{P}-\mathrm{C}$ and $-\mathrm{P}+\mathrm{C})$ than on the plots where prairie dogs remained $(+\mathrm{P}-\mathrm{C}$ and $+\mathrm{P}+\mathrm{C}$ ) (ANOVA, $F_{3,15}=31.32, P<0.0001 ; \mathrm{MM}$, time $\times$ treatment, $F_{6,19.6}=29.78, P<0.0001$; Fig. 5B). Two other common species of Melanoplus (M. arizonae and $M$. sanguinipes) were also 2-3 times more abundant on the $-\mathrm{P}-\mathrm{C}$ plots compared to the other three plots, with the largest differences being between the $-\mathrm{P}-\mathrm{C}$ and the $+\mathrm{P}+\mathrm{C}$ plots (ANOVA, $P<0.05$ for both; Appendix F). In contrast, another common grasshopper, Trimerotropis pallidipennis, showed a twofold decline in 2007 on the $+\mathrm{P}+\mathrm{C}$ plots compared to the $-\mathrm{P}-\mathrm{C}$ plots (ANOVA, $F_{3,15}=6.56, P=0.02$ ), and this pattern persisted in 2008 (Fig. 5C). Dactlylotum bicolor (ANOVA, $F_{3,15}=4.57, P=0.03$ ), and several other less common species, showed a similar pattern. For most of these grasshopper species the greatest differences $(2-3$ fold $)$ were consistently between the $-\mathrm{P}-\mathrm{C}$ and $+\mathrm{P}+\mathrm{C}$ plots, demonstrating a generally larger effect where cattle and prairie dogs co-occurred than where they were both absent or occurred alone.

\section{Small-mammal activity response}

Banner-tailed kangaroo rats showed a significant response to removal of prairie dogs and addition of cattle grazing (Fig. 6). Based on our mound survey and soil disturbance measurements, there were no significant differences in kangaroo rat, prairie dog, ant, or pocket gopher mound abundance or activity among treatments or blocks at the start of the study. Following treatment implementation, kangaroo rat activity increased significantly on the plots with only cattle $(-\mathrm{P}+\mathrm{C})$ relative to the other study plots, with a signficant time $\times$ treatment interaction effect found from spring 2006 through fall $2008\left(\mathrm{MM}\right.$, time $\times$ treatment, $\left.F_{15,54.1}=1.92, P=0.042\right)$.

\section{DisCUSSION}

Our manipulative experiment demonstrated that this desert grassland ecosystem responded rapidly and dramatically to the presence or absence of domestic cattle and a keystone burrowing rodent. Regardless of how their long-term impacts may play out, the shortterm effects documented here demonstrate the powerful controls these animals have on grasslands (Table 1). Other experimental studies have revealed similarly rapid responses to experimental exclusion of other mammalian herbivores, especially to burrowing mammals, including prairie dogs in other grassland systems (Cid et al. 1991, Fahnestock and Detling 2002, Retzer 2007, Van Staalduinen et al. 2007, Mokotjomela et al. 2009). Under the intensive cattle grazing regime that occurs elsewhere in the Janos grasslands, we expect that cattle would have even larger effects than observed in our experiment.

To the extent that our experiments provide tests, the results generally support the predictions of our conceptual model (i.e., plant architecture and species composition, animal associates, indirect effect of cattle on prairie dog abundance; Fig. 1, Table 1). These responses will likely become even more pronounced with time. They document the importance, not only of separate effects of the different functional groups of herbivores, but also interactive impacts. Indeed, the combined impacts on vegetation were synergistic, due not only to grazing by both prairie dogs and cattle, and engineering activities of prairie dogs, but also to the increase in prairie dog abundance in response to cattle grazing (Fig. 4). Therefore, consistently greater impacts where the species co-occurred reflect, in part, increases in prairie 

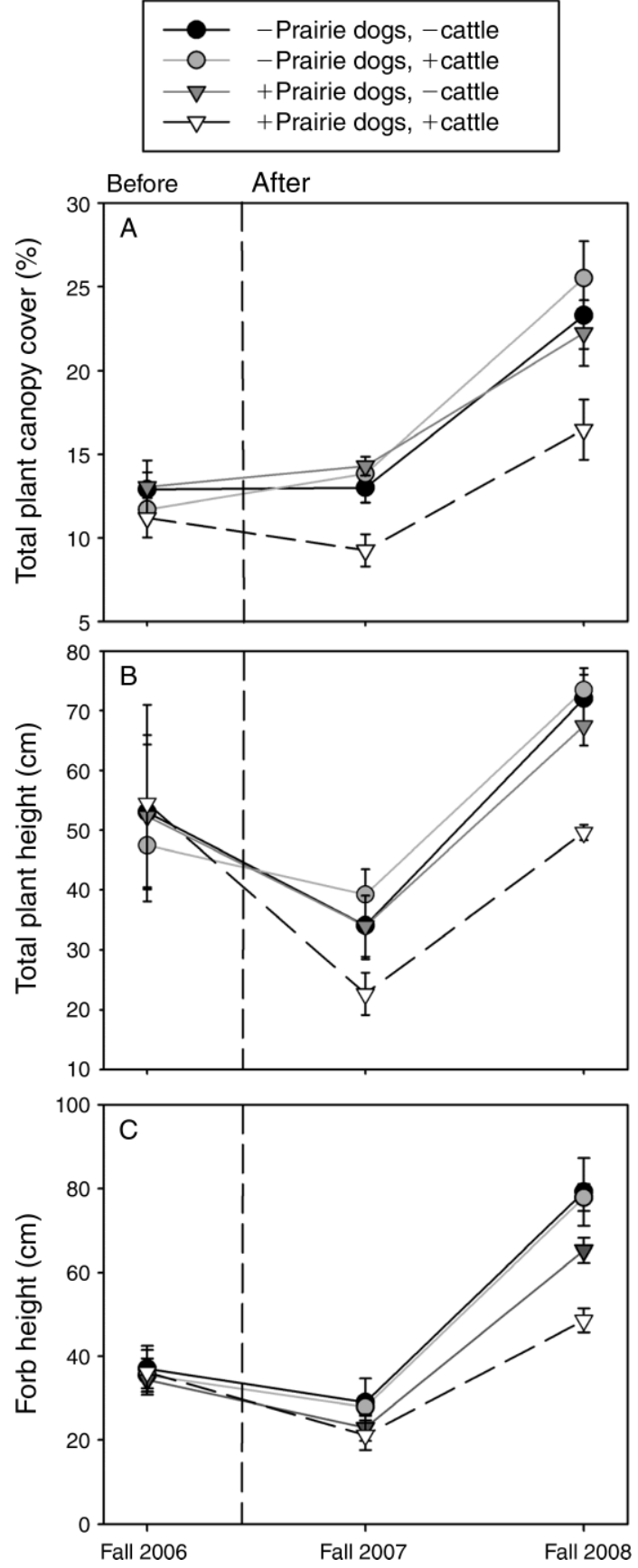

FIG. 4. (A) Canopy cover and (B) height of vegetation (both forbs and grasses combined), and (C) mean summer forb height (all values are means \pm SE) showing the rapid changes in trajectories across treatments over time, following the implementation of the treatments.

dog abundance, which was not only a treatment but also a response variable in our experiment. Consequently, the effect of prairie dogs was greater where they coexisted with cattle than where they occurred alone.

The large increase in banner-tailed kangaroo rat activity in areas with cattle shows that prairie dogs
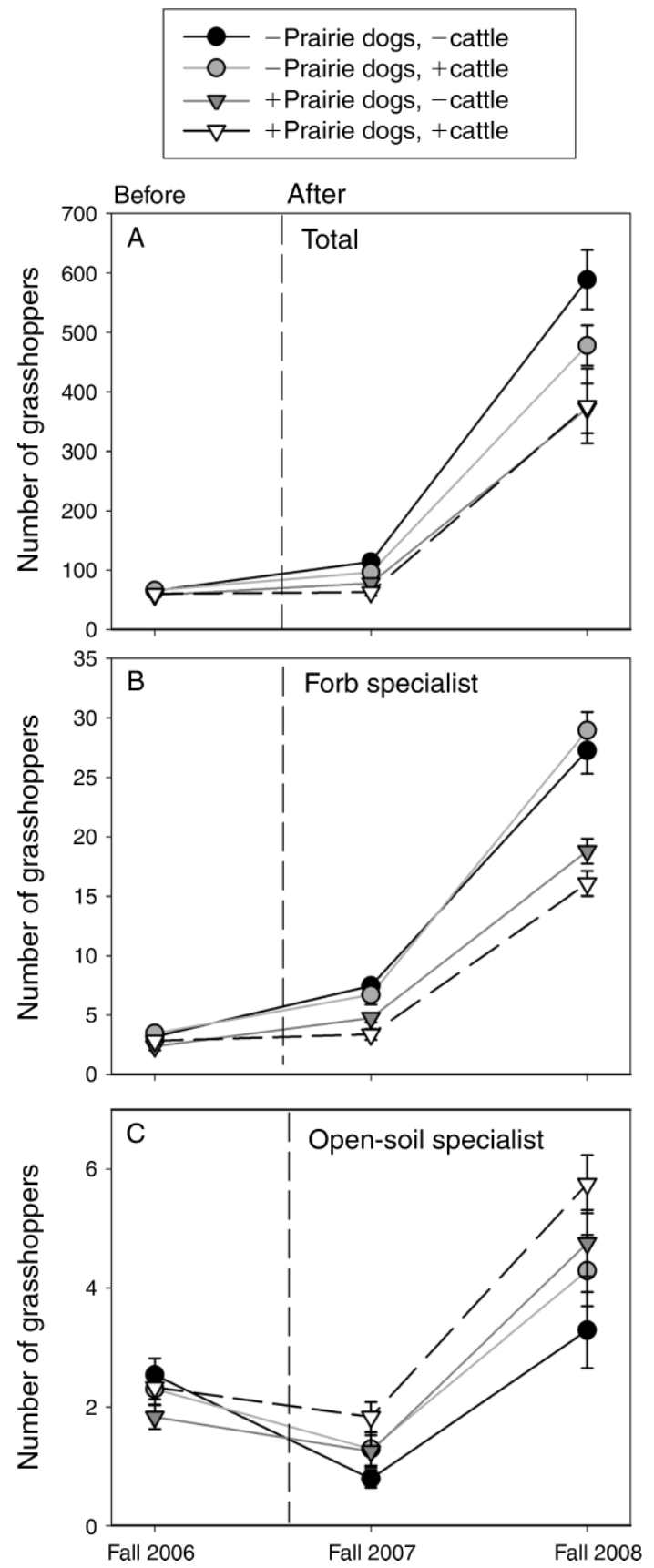

FIG. 5. Data show rapid changes in trajectories in mean abundance (per $50 \mathrm{~m}^{2}$ ) of (A) all grasshoppers, (B) the forb specialist grasshopper Melanoplus lakinus, and (C) the open-soil specialist grasshopper Trimerotropis pallidipennis (all values are means $\pm \mathrm{SE}$ ), following the implementation of the treatments.

and cattle had differentially impacted this coexisting keystone rodent (Valone et al. 1995). Despite the common coexistence of banner-tails and prairie dogs in these grasslands, previous work has suggested that these rodents compete (Davidson and Lightfoot 2006), and the current study supports this relationship. 


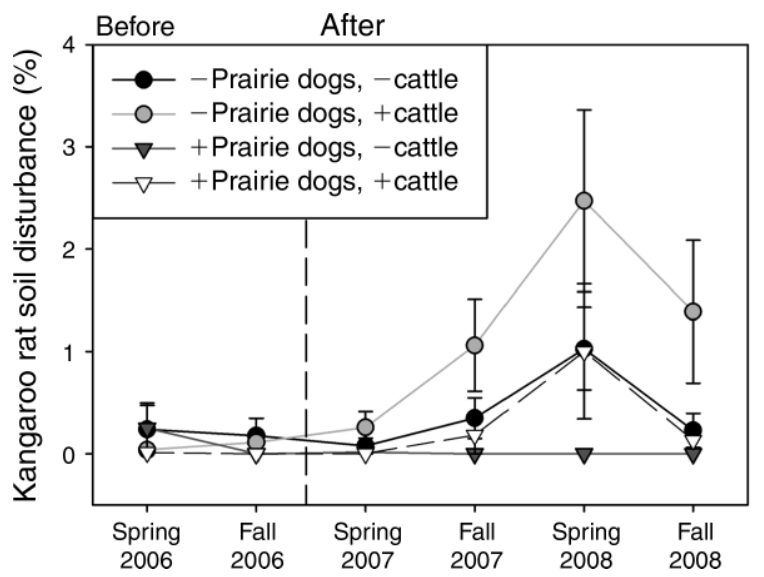

FIG. 6. Banner-tailed kangaroo rat activity (all values mean $\pm \mathrm{SE}$ ) on the different study plots, as measured by the percent cover of their soil disturbance. Note that the significant $(P<$ $0.05)$ increase is shown on plots with cattle only $(-\mathrm{P}+\mathrm{C})$.

Further, our results suggest that banner-tailed kangaroo rats benefit from moderate grazing by cattle, which reduces vegetation and creates preferred open habitat (Krogh et al. 2002), especially when there is no competition with prairie dogs. However, overgrazing to the point of desertification has caused large-scale declines in banner-tailed kangaroo rat populations (Krogh et al. 2002, Waser and Ayers 2003). Our experiments offer additional insights into the apparent relationships between these keystone rodent species and cattle, which may have important consequences for grassland biodiversity, in particular because many vertebrates and invertebrates are strongly dependent on the burrow mounds of banner-tails, prairie dogs, or both (Valone et al. 1995, Kotliar et al. 2006, Davidson and Lightfoot 2007, Davidson et al. 2008).

Prairie dogs had large independent effects on grasshoppers, but together prairie dogs and cattle, by altering both vegetation and soils, had the greatest impact on grasshopper assemblages. These findings are significant because grasshoppers are important herbivores of semiarid grassland ecosystems, representing diverse species assemblages and ecological attributes (Joern 1982). Impressively, grasshopper abundance and forb cover and height showed similar trends across treatments (Figs. 4 and 5). Grasshopper abundance has been found to be higher off prairie dog colonies where plant cover is greater (O'Meilia et al. 1982, Russell and Detling 2003, Davidson and Lightfoot 2007), similar to our findings, although grasshopper species associated with forbs and bare soil are typically more common on colonies due to the disturbance (Russell and Detling 2003, Davidson and Lightfoot 2007). We saw such patterns with species like $T$. pallidipennis and $D$. bicolor, which prefer sparse vegetation and benefited from the more open habitat created by both cattle and prairie dogs. However, forb specialists (e.g., Melanoplus) were more common on treatments without prairie dogs or either species, where forbs were taller and abundant (Figs. 3 and 4). Our results indicate a large response of insect herbivores to vegetation released from grazing by mammalian herbivores. While prairie dogs had distinctive impacts on grasshoppers, prairie dogs and cattle together had interactive effects, illustrated by the considerably greater differences in grasshopper species abundances where both prairie dogs and cattle were present compared to where they were alone or absent.

Some of the strongest impacts of cattle and prairie dogs on vegetation were where they co-occurred compared to where each occurred alone (Fig. 4). Prairie dogs and cattle are both well known to reduce vegetation height and perennial grass cover, resulting in increases in forbs and bare soil (Whicker and Detling 1988, Schlesinger et al. 1990). Although prairie dogs and moderate cattle grazing had no significant independent effects on vegetation height and plant cover in our study, prairie dogs and cattle together had strong combined effects (Fig. 4). Despite the observed reduction in vegetation height and cover, plots with both prairie dogs and cattle did not necessarily have lower primary production, since herbivore grazing is known to stimulate plant growth (Whicker and Detling 1988). Similar experimental studies have evaluated the combined impacts of prairie dogs and bison in mixed-grass prairies of the Great Plains, but no interactive effects were reported, perhaps because of very low bison numbers (Cid et al. 1991, Fahnestock and Detling 2002). The large combined impact of prairie dogs and cattle in our experiment resulted in part from increased prairie dog abundance where the two co-occurred, which was not observed by Cid et al. (1991). This positive relationship of prairie dogs with cattle grazing is consistent with previous reports and simulated grazing (Snell 1985, Cheng and Ritchie 2006, Curtin 2008), although it remains to be demonstrated whether these

TABLE 1. Summary of effects of prairie dogs and cattle on grassland community variables.

\begin{tabular}{lccc}
\hline \hline \multicolumn{1}{c}{ Variable } & $-\mathrm{P}+\mathrm{C}$ & $+\mathrm{P}-\mathrm{C}$ & $+\mathrm{P}+\mathrm{C}$ \\
\hline Prairie dog abundance & $\ldots$ & $\ldots$ & $\uparrow$ \\
Total plant height & $\mathrm{ns}$ & $\mathrm{ns}$ & $\downarrow$ \\
Summer forb height & $\mathrm{ns}$ & $\mathrm{ns}$ & $\downarrow$ \\
Plant canopy cover & $\mathrm{ns}$ & $\mathrm{ns}$ & $\downarrow$ \\
Plant biomass & $\mathrm{ns}$ & $\mathrm{ns}$ & $\mathrm{ns}$ \\
Total grasshopper abundance & $\mathrm{ns}$ & $\downarrow$ & $\downarrow$ \\
Forb specialist grasshopper & $\downarrow / \mathrm{ns}$ & $\downarrow / \mathrm{ns}$ & $\downarrow$ \\
$\quad$ abundance & $\mathrm{ns}$ & $\mathrm{ns}$ & $\uparrow$ \\
Open-soil specialist grasshopper & & & \\
$\quad$ abundance & & $\mathrm{n}$ & $\mathrm{ns}$ \\
Banner-tailed kangaroo rat activity & $\uparrow$ & $\mathrm{ns}$ & \\
\hline
\end{tabular}

Notes: The table demonstrates some of the independent effects of cattle and prairie dogs, and the consistently large effects of both cattle and prairie dogs where they co-occurred. The arrows indicate significant $(P<0.05)$ increases or decreases in those variables relative to the $-\mathrm{P}-\mathrm{C}$ plot, following the implementation of the treatments. Nonsignificant differences are indicated with "ns." In the case of forb specialist grasshoppers, some species decreased, while others showed no significant response (i.e., arrow/ns). 
responses reflect differences in the distribution of colonies or in overall abundance. This relationship is further influenced by the positive associations of cattle with prairie dog colonies. Our research in the Janos region is showing that cattle preferentially graze on prairie dog colonies (R. Sierra, E. L. Fredrickson, and G. Ceballos, unpublished data; see also Curtin 2008), similar to the preferential grazing by bison on colonies in mixed-grass prairie (Coppock et al. 1983). So, grasslands where cattle and prairie dogs coexist experience the combined effects of two major herbivores, and ecosystem structure and function are shaped fundamentally by the relationships between them.

Such relationships and resultant synergistic effects may be common between megaherbivores and burrowing mammals worldwide, and even between large and small herbivores more generally. For example, livestock are purported to facilitate other burrowing mammals, such as plateau pikas and zokors (Myospalax fontanierii) in the Tibetan plateau and plains vizcachas in the Pampas of Argentina (Jackson 1988, Smith and Foggin 1999, Zhang et al. 2003), while native megaherbivores like white rhinos (Ceratotherium simum) and elephants in Africa are known to facilitate smaller grazers, including impala (Aepyceros melampus), zebra (Equus burchelli), and others (Farnsworth et al. 2002, Waldram et al. 2008). However, much remains to be learned about how these relationships and their context dependencies translate into interactive impacts on grasslands. Recent studies have found that large domestic grazers have broader landscape-scale effects than burrowing mammals, which have more intensive, localized impacts due to their sedentary behavior and engineering activities (Retzer 2007, Van Staalduinen et al. 2007, Mokotjomela et al. 2009, Yoshihara et al. 2010). For these reasons and consistent with our model, small and large herbivores often have both independent and interactive impacts (e.g., Ritchie and Olff 1999, Olofsson et al. 2004, Bakker et al. 2006, Yoshihara et al. 2010). When each functional group is more abundant when the other is present than when they occur alone (e.g., Coppock et al. 1983, Whicker and Detling 1988, Arsenault and Owen-Smith 2002, Curtin 2008, the present study; R. Sierra et al., unpublished data), they can play synergistic roles in shaping the structure and function of grassland ecosystems.

Our conceptual model also has broader applications to other kinds of herbivores and ecosystem engineers in other grassland ecosystems, and highlights the need for both theoretical and empirical studies in order to better understand and manage grasslands throughout the world. More generally, our work demonstrates how the networks of ecological relationships among species belonging to different functional groups can affect the structure and function of ecosystems. These relationships and their consequential cascading effects are often controlled by top predators and humans (Ripple and Beschta 2007). Our findings are generally consistent with other studies, such as prairie dogs and kangaroo rats in Chihuahuan Desert grasslands (Davidson and Lightfoot 2006, 2007, 2008, Davidson et al. 2008), ants and prairie dogs in shortgrass prairie (Alba-Lynn and Detling 2008), habitat-modifying benthic mollusks in coastal regions (Boyer and Fong 2005), and salmon and bears in Alaskan riparian ecosystems (Helfield and Naiman 2006). Our study goes a step further, however, in showing that these combined effects are influenced by the relationships between species, and that these complex interactions can be important in the domesticated, human-dominated landscapes that now comprise most of the Earth (Kareiva et al. 2007). We suggest that grasslands may be able to sustain populations of both domestic megaherbivores and burrowing mammals when abundances are managed so that they interact synergistically to enhance the productivity and biodiversity of grassland ecosystems.

\section{ACKNOWLEDGMENTS}

We thank E. B. Erhardt, E. Bedrick, and A. NosedalSanchez for statistical advice, T. Lebgue for help with plant identifications, The Nature Conservancy (TNC) for use of El Uno Ecological Reserve, two anonymous reviewers for their comments on the manuscript, and E. Rivera, D. Aceves, O. Roacho, A. Gonzales, L. Martinez, V. Solis, J. Pacheco, S. N. Davidson, M. J. Hamilton, N. Barajas, and many others for help with fieldwork and logistical support. We also are grateful to S. N. Davidson for the artistic drawings of the bison, cow, and prairie dog in Fig. 1. This research was funded by NSF Grant OISE-0653296, Consejo Nacional de Ciencia y Tecnología, UNAM, the J. M. Kaplan Fund, TNC, and the Whitley Fund for Nature.

\section{Literature Cited}

Alba-Lynn, C., and J. K. Detling. 2008. Interactive disturbance effects of two disparate ecosystem engineers in North American shortgrass steppe. Oecologia 157:269-278.

Arsenault, R., and N. Owen-Smith. 2002. Facilitation versus competition in grazing herbivore assemblages. Oikos 97:313318.

Bagchi, S., T. Namgail, and M. E. Ritchie. 2006. Small mammalian herbivores as mediators of plant community dynamics in the high-altitude arid rangelands of TransHimalaya. Biological Conservation 127:438-442.

Bakker, E. S., M. E. Ritchie, H. Olff, D. G. Milchunas, and J. M. H. Knops. 2006. Herbivore impact on grassland plant diversity depends on habitat productivity and herbivore size. Ecology Letters 9:780-788.

Boyer, K. E., and P. Fong. 2005. Co-occurrence of habitatmodifying invertebrates: effects on structural and functional properties of a created salt marsh. Oecologia 143:619-628.

Branch, L. C., J. L. Hierro, and D. Villarreal. 1999. Patterns of plant species diversity following local extinction of the plains vizcacha in semi-arid scrub. Journal of Arid Environments 41:173-182.

Ceballos, G., A. Davidson, R. List, J. Pacheco, P. ManzanoFischer, G. Santos Barrera, and J. Cruzado. 2010. Rapid decline of a grassland ecosystem and its ecological and conservation implications. PLoS ONE 5:e8562.

Cheng, E., and M. E. Ritchie. 2006. Impacts of simulated livestock grazing on Utah prairie dogs (Cynomys pardivens) in a low productivity ecosystem. Oecologia 147:546-555.

Cid, M. S., J. K. Detling, A. D. Whicker, and M. A. Brizuela. 1991. Vegetational response of a mixed-grass prairie site 
following exclusion of bison and prairie dogs. Journal of Range Management 44:100-105.

Coppock, D. L., J. E. Ellis, J. K. Detling, and M. I. Dyer. 1983. Plant-herbivore interactions in a North American mixedgrass prairie. II. Responses of bison to modification of vegetation by prairie dogs. Oecologia 56:10-15.

Curtin, C. 2008. Interactions between cattle, prairie dogs, and small mammals in a desert grassland. Desert Plants 24:29-38.

Davidson, A. D., and D. C. Lightfoot. 2006. Keystone rodent interactions: prairie dogs and kangaroo rats structure the biotic composition of a desertified grassland. Ecography 29: 755-756.

Davidson, A. D., and D. C. Lightfoot. 2007. Interactive effects of keystone rodents on the structure of desert grassland arthropod communities. Ecography 30:515-525.

Davidson, A. D., and D. C. Lightfoot. 2008. Burrowing rodents increase landscape heterogeneity in a desert grassland. Journal of Arid Environments 72:1133-1145.

Davidson, A. D., D. C. Lightfoot, and J. M. McIntyre. 2008. Engineering rodents create key habitat for lizards. Journal of Arid Environments 72:2142-2149.

Derner, J. D., W. K. Laurenroth, P. Stapp, and D. J. Augustine. 2009. Livestock as ecosystem engineers for grassland bird habitat in the western Great Plains of North America. Rangeland Ecology and Management 62:111-118.

Detling, J. K. 2006. Do prairie dogs compete with livestock? Pages $65-88$ in J. L. Hoogland, editor. Conservation of the black-tailed prairie dog. Island Press, Washington, D.C., USA.

Fahnestock, J. T., and J. K. Detling. 2002. Bison-prairie dogplant interactions in a North American mixed-grass prairie. Oecologia 132:86-95.

Farnsworth, K. D., S. Focardi, and J. A. Beecham. 2002. Grassland-herbivore interactions: how do grazers coexist? American Naturalist 159:24-39.

Frank, D. A., S. J. McNaughton, and B. F. Tracy. 1998. The ecology of the Earth's grazing ecosystems: profound functional similarities exist between the Serengeti and Yellowstone. BioScience 48:513-521.

Gregorini, P., S. A. Gunter, P. A. Beck, K. J. Soder, and S. Tamminga. 2008. Review: The interaction of diurnal grazing pattern, ruminal metabolism, nutrient supply, and management in cattle. Professional Animal Scientist 24:308-318.

Helfield, J. M., and R. J. Naiman. 2006. Keystone interactions: salmon and bear in riparian forests of Alaska. Ecosystems 9: 167-180.

Holechek, J. L., A. Tembo, A. Daniel, M. J. Fusco, and M. Cardenas. 1994. Long-term grazing influences of Chihuahuan Desert rangeland. Southwestern Naturalist 39:342-349.

Huenneke, L. F., D. Clason, and E. Muldavin. 2001. Spatial heterogeneity in Chihuahuan Desert vegetation: implications for sampling methods in semi-arid ecosystems. Journal of Arid Environments 47:257-270.

Huntly, N., and R. Inouye. 1988. Pocket gophers in ecosystems: patterns and mechanisms. BioScience 38:786-793.

Jackson, J. E. 1988. Terrestrial mammalian pests in Argentina-an overview. Proceedings of the Vertebrate Pest Conference 13:196-198.

Joern, A. 1982. Vegetation structure and microhabitat selection in grasshoppers. Southwestern Naturalist 27:197-209.

Jones, C. G., J. H. Lawton, and M. Shachak. 1994. Organisms as ecosystem engineers. Oikos 69:373-386.

Kareiva, P., S. Watts, R. McDonald, and T. Boucher. 2007. Domesticated nature: shaping landscapes and ecosystems for human welfare. Science 316:1866-1869.

Knapp, A. K., J. M. Blair, J. M. Briggs, S. L. Collins, D. C. Hartnett, and L. C. Johnson. 1999. The keystone role of bison in North American tallgrass prairie. BioScience 49:39-50.

Kotliar, N. B., B. J. Miller, R. P. Reading, and T. W. Clark. 2006. The prairie dog as a keystone species. Pages 53-64 in J. L. Hoogland, editor. Conservation of the black-tailed prairie dog: saving North America's western grasslands. Island Press, Washington, D.C., USA.

Krogh, S. N., M. S. Zeisset, E. Jackson, and W. Whitford. 2002. Presence/absence of a keystone species as an indicator of rangeland health. Journal of Arid Environments 50:513519.

Lai, C. H., and A. T. Smith. 2003. Keystone status of plateau pikas (Ochotona curzoniae): effect of control on biodiversity of native birds. Biodiversity and Conservation 12:1901-1912.

Leibold, M. A. 1995. The niche concept revisited: mechanistic models and community context. Ecology 76:1371-1382.

McNaughton, S. J. 1984. Grazing lawns: animals in herds, plant form, and coevolution. American Naturalist 124:863-886.

Miller, B. J., R. P. Reading, D. E. Biggins, J. K. Detling, S. C. Forrest, J. L. Hoogland, J. Javersak, S. D. Miller, J. Proctor, and J. C. Truett. 2007. Prairie dogs: an ecological review and current biopolitics. Journal of Wildlife Management 71: 2801-2810.

Mokotjomela, T., U. Schwaibold, and N. Pillay. 2009. Does the ice rat Otomys sloggetti robertsi contribute to habitat change in Lesotho? Acta Oecologica-International Journal of Ecology $35: 437-443$.

Olofsson, J., S. Stark, and L. Oksanen. 2004. Reindeer influence on ecosystem processes in the tundra. Oikos 105:386-396.

O'Meilia, M. E., F. L. Knopf, and J. C. Lewis. 1982. Some consequences of competition between prairie dogs and beef cattle. Journal of Range Management 35:580-585.

Owen-Smith, N. 1987. The pivotal role of megaherbivores. Paleobiology 13:351-362.

Paulsen, H. A., and F. N. Ares. 1962. Grazing values and management of black grama and tobosa grasslands and associated shrub ranges of the Southwest. USDA Technical Bulletin 1270, Washington, D.C., USA.

Power, M. E., D. Tilman, J. A. Estes, B. A. Menge, W. J. Bond, L. S. Mills, J. Daily, C. Castilla, J. Lubchenco, and R. T. Paine. 1996. Challenges in the quest for keystones. BioScience 46:609-620.

Pringle, R. M. 2008. Elephants as agents of habitat creation for small vertebrates at the patch scale. Ecology 89:26-33.

Retzer, V. 2007. Forage competition between livestock and Mongolian Pika (Ochotona pallasi) in Southern Mongolian mountain steppes. Basic and Applied Ecology 8:147-157.

Ripple, W. J., and R. L. Beschta. 2007. Restoring Yellowstone's aspen with wolves. Biological Conservation 138:514-519.

Ritchie, M. E., and H. Olff. 1999. Herbivore diversity and plant dynamics: compensatory and additive effects. Pages 175-204 in $\mathrm{H}$. Olff, V. K. Brown, and R. H. Drent, editors. Herbivores: between plants and predators. Blackwell Science, Oxford, UK.

Russell, R. E., and J. K. Detling. 2003. Grasshoppers (Orthoptera: Acrididae) and black-tailed prairie dogs (Sciuridae: Cynomys ludovicianus (Ord)): associations between two rangeland herbivores. Journal of the Kansas Entomological Society 76:578-587.

SAS Institute. 2005. SAS system for Microsoft Windows. SAS Institute, Cary, North Carolina, USA.

Schlesinger, W. H., J. F. Reynolds, G. L. Cunningham, L. F. Huenneke, W. M. Jarrell, R. A. Virginia, and W. G. Whitford. 1990. Biological feedbacks in global desertification. Science 247:1043-1048.

Smith, A. T., and M. J. Foggin. 1999. The plateau pika (Ochotona curzoniae) is a keystone species for biodiversity on the Tibetan plateau. Animal Conservation 2:235-240.

Snell, G. P. 1985. Results of control of prairie dogs. Rangelands $7: 30$.

Suttie, J. M., S. G. Reynolds, and C. Batello, editors. 2005. Grasslands of the world. Food and Agriculture Organization of the United Nations, Rome, Italy.

Towne, G. E., D. C. Hartnett, and R. C. Cochran. 2005. Vegetation trends in tallgrass prairie from bison and cattle grazing. Ecological Applications 15:1550-1559. 
Valone, T. J., J. H. Brown, and C. L. Jacobi. 1995. Catastrophic decline of a desert rodent, Dipodomys spectabilis: insights from a long-term study. Journal of Mammalogy 76:428-436.

Van Staalduinen, M. A., H. During, and M. J. A. Werger. 2007. Impact of grazing regime on a Mongolian forest steppe. Applied Vegetation Science 10:299-306.

Waldram, M. S., W. J. Bond, and W. D. Stock. 2008 Ecological engineering by a mega-grazer: white rhino impacts on a South African savanna. Ecosystems 11:101-112.

Waser, P. M., and J. M. Ayers. 2003. Microhabitat use and population decline in banner-tailed kangaroo rats. Journal of Mammalogy 84:1031-1043.

Weltzin, J. F., S. Archer, and R. K. Heitschmidt. 1997. Smallmammal regulation of vegetation structure in a temperate savanna. Ecology 78:751-763.
Whicker, A. D., and J. K. Detling. 1988. Ecological consequences of prairie dog disturbances: prairie dogs alter grassland patch structure, nutrient cycling, and feeding-site selection by other herbivores. BioScience 38:778-785.

Whitford, W. G., and F. R. Kay. 1999. Biopeturbation by mammals in deserts: a review. Journal of Arid Environments 41:203-230.

Yoshihara, Y., T. Okuro, B. Buuveibaatar, J. Undarmaa, and K. Takeuchi. 2010. Complementary effects of disturbance by livestock and marmots on the spatial heterogeneity of vegetation and soil in a Mongolian steppe ecosystem. Agriculture, Ecosystems and Environment 135:155-159.

Zhang, Y., Z. Zhang, and J. Liu. 2003. Burrowing rodents as ecosystem engineers: the ecology and management of plateau zokors Myospalax fontanierii in alpine meadow ecosystems on the Tibetan Plateau. Mammal Review 33:284-294.

\section{APPENDIX A}

Schematic diagram showing the $2 \times 2$ factorial design (Ecological Archives E091-224-A1).

\section{APPENDIX B}

Schematic diagram showing the replicated experimental blocks of plots (Ecological Archives E091-224-A2).

\section{APPENDIX C}

Photo showing accessibility of the prairie dog exclosure plots by the next largest rodent at the study site, the banner-tailed kangaroo rat (Ecological Archives E091-224-A3).

\section{APPENDIX D}

Photo of a typical prairie dog coterie patch, and graph of the number of prairie dogs observed on each of the treatment plots (Ecological Archives E091-224-A4).

\section{APPENDIX E}

Detailed methods of the cattle treatments (Ecological Archives E091-224-A5).

\section{APPENDIX F}

A table of statistical metrics for all significant ANOVA results (Ecological Archives E091-224-A6).

\section{APPENDIX G}

Graph showing precipitation amounts at (or near) the study site (Ecological Archives E091-224-A7). 